\title{
Similar prevalence of respiratory symptoms and atopy in Estonian schoolchildren with changing lifestyle over 4 yrs
}

\author{
M-A. Riikjärv*, T. Annus*, L. Bråbäck**, K. Rahu***, B. Björkstén ${ }^{+,++}$
}

Similar prevalence of respiratory symptoms and atopy in Estonian schoolchildren with changing lifestyle over 4 yrs. M-A. Riikjärv, T. Annus, L. Brabäck, K. Rahu, B. Björkstén. (C) ERS Journals Ltd 2000.

ABSTRACT: The prevalence of allergic sensitization and clinical manifestations is low in Eastern Europe, despite a continuous increase in industrialized countries with a market economy. The aim of the present study was to study changes in the prevalence of respiratory symptoms and atopic sensitization over time among schoolchildren in Estonia, in relation to environmental changes as the country transformed into a market economy.

A cross-sectional study of 10-yr-old children was carried out between October 1996 and April 1997, employing a questionnaire regarding the prevalence of wheezing, rhinitis and itching rash $(n=979)$ and skin-prick tests with seven inhalant allergens $(n=640)$. The results were compared with those of a similar study performed in 1992 1993.

The 12-month prevalence of wheeze was $8.3 \%$, as compared to $9.4 \%$ in $1992-1993$ (Ns) and of asthma was 2.5 versus $3.2 \%$ (NS). The prevalence of a positive skin-prick test result was $14.3 \%$ in both studies. Furthermore, the prevalence of sensitivity to the individual allergens was similar, except for a significantly higher prevalence of dog sensitivity in 1996-1997 (4.7 versus $2.0 \%)$.

The prevalence of respiratory and other potentially allergic symptoms, as well as the prevalence of atopic sensitization, remains low in Estonian 10-yr-old children, despite a changing lifestyle over the past 4 yrs. This could indicate that the time period was too short for environmental changes to affect the prevalence of allergy, or alternatively that risk factors associated with a "western lifestyle" are of particular significance earlier in life.

Eur Respir J 2000; 16: 86-90.

\begin{abstract}
*Tallinn Children's Hospital, Tallinn, Estonia. **Dept of Paediatrics, Sundsvall Hospital, Sundsvall, Sweden. ***Dept of Epidemiology and Biostatistics, Institute of Experimental and Clinical Medicine, Tallinn, Estonia. 'Dept of Paediatrics, University Hospital, Linköping, Sweden.

${ }^{++}$Dept of Paediatrics, Tartu University, Tartu, Estonia.
\end{abstract}

Correspondence: B. Björkstén, Centre for Allergy Research, Karolinska Institute, Faculty of Health Sciences, S-171 77 Stockholm, Sweden. Fax: 468327196

Keywords: Allergy

asthma

children

eczema

prevalence

rhinitis

Received: August 31999

Accepted after revision March 192000

The study was supported by grants from GlaxoWellcome, Stevenage, UK and the Swedish Institute.
Epidemiological studies repeated several years apart in the same area have revealed an increasing prevalence of asthma-like respiratory symptoms and verified asthma among schoolchildren in industrialized countries [1, 2]. Furthermore, there are large worldwide differences in the prevalence of allergic diseases, as shown by phase I of the International Study of Asthma and Allergies in Childhood (ISAAC), using standardized protocols for international comparisons [3-5]. Within these global differences, the European geographical West/East gradient of the prevalence has received particular attention [6]. Several factors, characteristic of the "western lifestyle", have been the subject of research and proposed as triggers for the higher sensitization and allergy prevalence, e.g. socioeconomic status, family size, diet, housing conditions and increased allergen exposure, as well as changes in the microbial flora. The rapid increase in the prevalence of hay fever and atopic sensitization among schoolchildren in a recent study from former Eastern Germany points towards the importance of lifestyle factors for sensitization [7].

A survey carried out in 1992-1993 revealed a low prevalence of asthma-like respiratory symptoms and atopy in Estonian school children [8]. As substantial changes in everyday lifestyle, e.g. food consumption and indoor cli- mate, have occurred since independence in 1991, it was hypothesized that this could have resulted in an increasing prevalence of allergy. The aim of the present study was, therefore, to assess the prevalence of respiratory symptoms and atopic sensitization among 10-11-yr-old schoolchildren who had spent their first 4-5 yrs of life under Soviet conditions, and were then exposed to a changing lifestyle during the following 6 yrs. The results were compared to a similar study performed 4 yrs previously.

\section{Methods}

\section{Study population}

The study was carried out between October 1996 and April 1997 in Tallinn, the capital of Estonia, situated on the southern coast of the Baltic Sea with a population of 480,000 . The study group comprised 1,158 children aged 10 yrs ( 10 yrs to 11 yrs 0 months) from 20 schools. The schools were randomly selected from all Estonian-speaking elementary and secondary schools for nondisabled children in Tallinn, fulfilling the criteria of phase II of the 
International Study of Asthma and Allergies in Childhood (ISAAC). In the initial study in 1992-1993 [8], 806 children aged 11-12 yrs were randomly selected from 11 schools in Tallinn.

A questionnaire developed within phase II of the ISAAC, regarding respiratory symptoms and asthma, rhinitis and eczema was distributed through the schools to the parents for completion. The questions about wheezing in the past year, exercise wheezing, hay fever, itching rash (eczema) and asthma diagnosed by a doctor were similar, although not identical, in the two surveys (see Appendix). Thus, in the 1992-1993 survey, wheezing was related to certain trigger factors, whereas in the 1996-1997 study, this was not the case. Furthermore, in the questionnaire employed in 1992-1993, eczema was described in some detail, whereas, in 1996-1997, it was merely referred to as "itchy rash".

The questionnaire was completed by the parents of 979 of the 1,158 children $(85 \%)$ who were invited to participate in the study during the study period November 1996 to February 1997. In the study performed between October 1992 and February 1993, the response rate was 750 of 806 invited, i.e. $93 \%$.

\section{Skin-prick tests}

Skin-prick tests (SPT) were performed on the volar aspects of the forearm with seven common standardized allergen extracts (Dermatophagoides pteronyssinus, D. farinae, birch and timothy grass pollen, Alternaria, and cat and dog dander), Soluprick ${ }^{\mathrm{TM}}$, (ALK, Hørsholm, Denmark), in March-April 1997, using ALK lancets. Histamine dihydrochloride $10 \mathrm{mg} \cdot \mathrm{mL}^{-1}$ was used as positive control and 50\% glycerol as negative control. The prick tests were performed according to the instructions of the European Academy of Allergy and Clinical Immunology (EAACI) [9]. The test procedure and the potency and source of the extracts were thus the same as in 1992-1993 [8]. The two fieldworkers were instructed and trained as previously described [8], and checked for consistency during the fieldwork according to the ISAAC manual for phase II (module 3.1). A child was considered to be sensitized if a weal reaction to any allergen was $\geq 3 \mathrm{~mm}$, calculated as the sum of the longest and the midpoint orthogonal diameters divided by two. Atopy was defined by at least one positive SPT. The participation rate for SPTs was $66 \%$ (643/979), as compared to $78 \%$ in $1992-$ 1993. The difference in participation rate was due to parental reluctance to permit skin-prick testing. Three children showed a positive reaction to the negative control, and were therefore excluded from the analysis. During the SPT procedure, the skin was also studied for atopic dermatitis, employing the manual developed within the ISAAC phase II (module 3.2).

\section{Statistical analysis}

Data entry and calculation of prevalence rates were performed using the microsoft database management system FOX.PRO. For testing the differences in prevalence between groups, the prevalence odds ratio (POR) was employed. The $95 \%$ confidence intervals (CIs) were calculated using the CIA program for the calculation of confidence intervals [10]. The weighted prevalence of atopic sensitization for the whole group was calculated. Assuming a $1 \%$ increase in allergic manifestations per year [1], the power was $80 \%$ for detecting a difference between the two studies.

\section{Ethical aspects}

The Ethics Committee of the Institute of Experimental and Clinical Medicine in Tallinn, Estonia approved the study. Approval to conduct the survey was also obtained from the Municipality Education Department and school principals. Written consent was obtained from the parents of all children studied.

\section{Results}

The 12-month prevalence of wheezing and exercise wheezing, as well as the lifetime prevalence of asthma, was similar in the two surveys in 1996-1997 and 1992-1993 (table 1). There was, however, an increase in the prevalence of night cough and itching rash (eczema). Five per cent of the children had at least one symptom of atopic dermatitis, most frequently expressed as a rash in the fold of the elbows, revealed on examination of the skin for flexural dermatitis during SPTs. The lifetime prevalence of wheezing was $19.9 \%$, sneezing or a blocked nose in the absence of a cold $21.2 \%$ and itching rash $24.6 \%$.

The prevalence of atopic sensitization, expressed by at least one positive reaction to any allergen, as well as to grass pollen, were similar in 1992 and 1997 (table 2). As not all children underwent atopy testing, weighted calculation was used to determine the sensitivity prevalence in the whole population, which resulted in an identical figure of $14.3 \%$ for the two studies. The only significant difference between the two study groups was a higher prevalence of sensitivity to dog dander in 1997 (POR 2.4, 95\% CI 1.2-4.7). There was also a trend towards an increase in the prevalence of sensitivity to cat and birch, and a slight decrease in sensitivity to D. pteronyssinus. The mean diameter of the histamine weals was $5.9 \mathrm{~mm}$, as compared to $4.5 \mathrm{~mm}$ in 1992-1993 (Ns).

Table 1. - Prevalence of respiratory symptoms, allergic disorders and asthma in Estonian 10-11-yr-old schoolchildren

\begin{tabular}{|c|c|c|c|}
\hline & \multicolumn{2}{|c|}{ Prevalence \% } & \multirow{2}{*}{$\begin{array}{c}\text { POR } \\
(95 \% \mathrm{CI})\end{array}$} \\
\hline & 1996-1997 & 1992-1993 & \\
\hline Subjects $n$ & 979 & 753 & \\
\hline Wheeze & $8.3(2)$ & $9.4(1.1)$ & $0.9(0.6-1.2)$ \\
\hline Exercise wheezing* & $5.6(4)$ & $5.7(1.2)$ & $1.0(0.7-1.5)$ \\
\hline Night cough & $9.2(5)$ & $5.1(1.3)$ & $1.9(1.3-2.8)$ \\
\hline Hay fever & $6.1(7)$ & $7.4(3)$ & $0.8(0.6-1.2)$ \\
\hline Itching rash* & $20.0(9)$ & 14.9 (4) & $1.6(1.2-2.1)$ \\
\hline $\begin{array}{l}\text { Diagnosed asthma } \\
\text { ever }\end{array}$ & $2.5(3)$ & $3.2(2)$ & $0.8(0.4-1.3)$ \\
\hline
\end{tabular}

*: considerable difference between questions in the two surveys. Current results are compared with the previous study in 19921993 [8]. Figures in parentheses refer to the questions in the two surveys (see Appendix). POR: prevalence odds ratio; CI: confidence interval. 
Table 2. - Weighted prevalence rates of atopic sensitization (weal size $\geq 3 \mathrm{~mm}$ ) to inhalant allergens among Estonian schoolchildren in 1992-1993 and 1996-1997

\begin{tabular}{|c|c|c|c|c|c|}
\hline & \multicolumn{3}{|c|}{ Prevalence of SPT positivity $\%$} & \multicolumn{2}{|c|}{ Mean weal diameter mm* } \\
\hline & 1997 & 1992 & POR $(95 \% \mathrm{CI})$ & 1997 & 1992 \\
\hline Subjects $n$ & 640 & 589 & & 640 & 589 \\
\hline Histamine & & & & $5.9 \pm 0.4$ & $4.5 \pm 0.4$ \\
\hline Dermatophagoides pteronyssinus & 4.4 & 6.1 & $0.7(0.4-1.2)$ & $4.8 \pm 0.3$ & $4.1 \pm 0.2$ \\
\hline Dermatophagoides farinae & 4.0 & - & - & $4.3 \pm 0.4$ & - \\
\hline Cat & 7.2 & 6.1 & $1.2(0.8-1.9)$ & $5.5 \pm 0.3$ & $5.0 \pm 0.3$ \\
\hline Dog & 4.7 & 2.0 & $2.4(1.2-4.7)$ & $4.1 \pm 0.3$ & $4.2 \pm 0.3$ \\
\hline Timothy grass & 4.8 & 4.8 & $1.0(0.6-1.7)$ & $5.6 \pm 0.5$ & $5.5 \pm 0.5$ \\
\hline Birch & 4.1 & 2.5 & $1.6(0.9-3.1)$ & $5.3 \pm 0.4$ & $4.1 \pm 0.2$ \\
\hline Alternaria & 0.6 & 0.2 & $3.7(0.4-33.2)$ & $3.8 \pm 0.6$ & - \\
\hline$\geq 1$ positive to any allergen & 14.3 & 14.3 & $1.0(0.8-1.4)$ & & \\
\hline
\end{tabular}

*: for positve reactions, mean \pm SEM. SPT: skin-prick test; POR: prevalence odds ratio; CI: confidence interval.

As SPTs were performed in only $66 \%$ of the study group, analysis of the drop-outs was performed. The prevalence of wheezing, asthma, exercise wheeze, night cough, hay fever and eczema was similar in children who were and were not skin-prick tested (data not shown).

The prevalence of different symptoms of allergic disease in relation to atopic sensitization is presented in table 3 . Most of the asthma-like respiratory symptoms, and also asthma, rhinitis and eczema, were more common in SPTpositive children. The risk of wheezing (lifetime and last year wheezing), if atopic, was higher in females than in males (the POR for 12-month wheezing was 3.5 (95\% CI 1.4-9.1) in females and 1.6 (95\% CI 0.6-3.9) in males).

Seventy per cent of the children lived in apartments, as compared to $76 \%$ in $1992-1993$ (NS), and $66 \%$ of the families had three rooms or less. Most families (80\%) had one or two children. Less than $10 \%$ reported indoor dampness, as compared to $29 \%$ in $1992-1993$ ( $p<0.01$ ). Although $55 \%$ of the families perceived the indoor air as too dry, $78 \%$ regarded the ventilation as adequate.

There have been significant changes in diet since the country became independent. Thus the consumption of margarine had increased over the past $5 \mathrm{yrs}$ in $47 \%$ of the families, oil consumption in $58 \%$, vegetables in $35 \%$ and fruit in $72 \%$.

\section{Discussion}

The prevalence of respiratory and other potentially allergic symptoms, as well as the prevalence of atopic sensitization, expressed by at least one positive SPT, remained low in Estonian schoolchildren over a 4-yr period. The SPTs were performed in an identical way in the two studies. Both surveys were conducted in the same area and during the same seasons. The response rate was high in both studies, i.e. 85\% and 93\% respectively in 1996-1997 and 1992-1993. The nonresponders did not differ from the responders regarding sex or living area. Since many of the families did not have a telephone, the nonresponders could not be contacted, and an in-depth analysis of the reasons for not responding could, therefore, not be carried out. Furthermore, the prevalence of symptoms was similar in children undergoing skin-prick testing and those declining skin-prick testing, both in the present and the previous study [8].

Although the questionnaires in the studies were not identical, the authors believe their conclusions to be reasonable, especially as they are supported by the SPT results. In 1992-1993, but not in 1996-1997, wheezing was enquired about in connection with triggering factors. This would mean that all wheezing episodes, independent

Table 3. - Prevalence (\%) of clinical symptoms and asthma, in relation to atopic sensitization, among Estonian schoolchildren in 1996-1997

\begin{tabular}{|c|c|c|c|c|}
\hline \multirow{2}{*}{ Symptom } & \multirow{2}{*}{ Subjects $n$} & \multicolumn{2}{|c|}{ Skin-prick test $\mathrm{n}$} & \multirow{2}{*}{ POR $(95 \% \mathrm{CI})$} \\
\hline & & Positive & Negative & \\
\hline Subjects $n$ & & 94 (59 male) & 544 (241 male) & \\
\hline Wheezing ever & 137 & 33 & 20 & $2.0(1.3-3.3)$ \\
\hline Wheezing 12 months & 53 & 15 & 7 & $2.3(1.2-4.4)$ \\
\hline Night cough 12 months & 65 & 10 & 10 & $0.9(0.4-1.9)$ \\
\hline Exercise wheeze 12 months & 55 & 11 & 5 & $2.2(1.0-4.7)$ \\
\hline Sneezy, runny nose ever & 148 & 34 & 21 & $1.9(1.2-3.0)$ \\
\hline Sneezy, runny nose 12 months & 119 & 33 & 16 & $2.5(1.6-4.1)$ \\
\hline Asthma ever & 15 & 6 & 2 & $4.1(1.4-11.7)$ \\
\hline Hay fever ever & 31 & 12 & 4 & $3.5(1.6-7.5)$ \\
\hline \multicolumn{5}{|l|}{ Wheeze ever } \\
\hline Males & 73 & 31 & 23 & $1.5(0.8-2.8)$ \\
\hline Females & 64 & 37 & 17 & $2.9(1.4-6.2)$ \\
\hline \multicolumn{5}{|l|}{ Wheeze 12 months } \\
\hline Males & 26 & 12 & 8 & $1.6(0.6-3.9)$ \\
\hline Females & 27 & 20 & 7 & $3.5(1.4-9.1)$ \\
\hline
\end{tabular}


of triggering factors, were reported in the second study and thus tended to increase the prevalence of wheezing. Similarly, episodic night cough was included in the second study, which would increase the reported prevalence of night cough.

Episodic symptoms are not well recorded by parents, as indicated by a previously reported low level of agreement between questionnaires completed by the parents and the adolescents themselves [11]. This problem was similar, however, in the two studies. Furthermore, the questions about hay fever in the two questionnaires were comparable.

The children were slightly younger in the present study, since it was performed as part of the European part of the ISAAC phase II. There are no indications, however, that the minor age difference among the preadolescent children (1 yr) in the two studies would have significantly influenced the results. Furthermore, it has been shown that the largest rise in serum immunoglobulin E levels occurs between 1 and 2 yrs of age [12].

The SPTs were performed using identical methodology and great care was taken to ensure that this test procedure did not vary over time. An increasing prevalence of sensitivity to dog allergen was the only significant change in allergen sensitivity between the present and the previous study [8]. In addition, there was a trend towards a decrease in mite sensitivity and an increasing sensitivity to birch pollen and cat dander. These observations could possibly indicate that the prevalence of sensitivity is beginning to increase. The slightly lower prevalence of mite sensitivity could be explained by less exposure due to lower indoor temperatures in Estonian homes in recent years [13].

The short time-span between the two surveys could explain the stable prevalence of allergic respiratory symptoms and positive SPTs in the Estonian schoolchildren. A constant prevalence of allergic respiratory symptoms was also reported in children in former Eastern and Western Germany over the last 4 yrs [7, 14], whereas an increase in asthma-related symptoms was reported in adults in former Eastern Germany over a 4-year period [15]. This increase was related to greater self-awareness, rather than indicating a true increase.

A significant increase in hay fever was, however, reported in one study from former Eastern Germany [7]. This increase was explained by the extensive changes in the environment that had taken place after the re-unification of Germany. The largest increase in atopic sensitization among schoolchildren in former Eastern Germany was recorded against birch and grass pollens, whereas there was no increase in sensitivity to dog and cat allergen [7]. As the proportion of children who were tested during and outside the pollen season was not stated, it cannot be excluded that seasonal differences could have influenced the results. Furthermore, an increase in the prevalence of sensitization to inhalant allergens in preschool children in former Eastern Germany could not be confirmed in another study employing a radioallergosorbent test [14].

The extent of changes in living conditions in formerly socialist countries is difficult to assess. There was an increase in the ownership of cats and dogs corresponding to the increase in atopic sensitization to cat and dog in former Eastern Germany [7]. Margarine and oil consumption has increased in schoolchildren in former Eastern
Germany [7] and in Estonia, both in the present and in another study from Estonia [16]. The levels of indoor allergens are similar in Estonia and Sweden [13]. These data indicate that either the influence of the new environment has been too short lasting and weak or "Western" lifestyle and other environmental factors are particularly important in the development of sensitization early in life, as suggested by prospective studies [17].

Atopic manifestations in children are strongly associated with wheezing illnesses in industrialized countries with a market economy $[18,19]$. A strong correlation between recurrent wheeze and sensitization has been reported in some [20], but not all studies [21, 22]. The association between atopy, as indicated by a positive SPT, and wheezing was fairly low in Estonia in 1992-1993 [8], and it remained low in the present study. The association was higher in female than in male schoolchildren, although sensitization was twice as common in male schoolchildren. The low correlation between wheeze and sensitization indicates that wheezing in Estonian schoolchildren is mostly of nonatopic origin.

In conclusion, there were no changes in the prevalence of asthma, allergic rhinitis, respiratory symptoms and atopic sensitization over 4 yrs in 10-11-yr-old schoolchildren in Estonia, despite a changed environment at that age. The findings support most, but not all, previous reports from united Germany and may lend support to the hypothesis that environmental factors associated with an increased risk of sensitization are particularly important during the first few years of life.

\section{Appendix}

Questions employed in the two surveys in 1996-1997 and 1992-1993.

\section{6-1997}

1. Has your child ever had wheezing or whistling in the chest at any time in the past?

2. Has your child had wheezing or whistling in the chest in the last 12 months?

3. Has your child ever had asthma?

4. In the last 12 months, has your child's chest sounded wheezy during or after exercise.

5. in the last 12 months, has your child had a dry cough at night, apart from a cough associated with a cold or chest infection?

6. Has your child ever had a problem with sneezing or a runny or blocked nose, when he/she DID NOT have a cold or the flu?

7. In the past 12 months, has your child had a problem with sneezing or a runny or blocked nose, when he/she DID NOT have a cold or the flu?

8. Has your child ever had hay fever?

9. Has your child had an itchy rash at any time in the last 12 months?

\section{2-1993}

1. Has your child experienced any of the following symptoms in the past year? 
1.1. Wheezing in the chest during e.g. a cold, physical exertion or in contact with animals?

1.2. Chest tightness and breathlessness during e.g. a cold, physical exertion and/or in contact with animals in the past year?

1.3. Nocturnal cough for a period longer than 4 weeks (without signs of cold or whooping cough) in the past year?

2. Has a doctor ever diagnosed your child as being asthmatic?

3 . Typical symptoms of allergic reactions in the nose and eye are: a runny or blocked up nose, itchiness around the nose and persistent sneezing together with red itchy eyes. The most common cause of this is animals and pollen. Has your child experienced any of the symptoms described above over the past year (the past 12 months)?

4. Eczema in children is most often seen on the inside of the elbows and backs of knees, on the neck, on the ankles, on the wrists and on the back of the hands. Eczema on the back of the thighs and on the buttocks is also quite common. Teenagers sometimes get eczema on the face and the neck, especially around the eyes. The skin is usually dry and itchy and the eczema can improve or even disappear during the summer. Has your child displaced any of the symptoms described above over the past year (the last 12 months)?

\section{References}

1. Burr M, Butland B, King S, Vaughan-Williams E. Changes in asthma prevalence: two surveys 15 years apart. Arch Dis Child 1989; 64: 1424-1456.

2. Burney P, Chinn S, Rona R. Has the prevalence of asthma increased in children? Evidence from the national study of health and growth 1973-86. BMJ 1990; 300: 1306-1310.

3. Strachan D, Sibbald B, Weiland S, et al. Worldwide variations in the prevalence of allergic rhinoconjunctivitis in children: International Study of Asthma and Allergies in Childhood (ISAAC). Pediatr Allergy Immunol 1997; 8: 161-176.

4. Asher M, Anderson $\mathrm{H}$, Crane J, et al. Worldwide variations in the prevalence of asthma symptoms: International Study of Asthma and Allergies in Childhood (ISAAC). Eur Respir J 1998; 12: 315-335.

5. The International Study of Asthma and Allergies in Childhood (ISAAC) Steering Committee. Worldwide variation in the prevalence of asthma and allergies: the International Study of Asthma and Allergies in Childhood (ISAAC). Lancet 1998; 351: 1225-1232.

6. Björkstén B, Dumitrascu D, Foucard T, et al. Prevalence of childhood asthma, rhinitis and eczema in Scandinavia and Eastern Europe. Eur Respir J 1998; 12: 432-437.
7. von Mutius E, Weiland S, Fritzsch C, Duhmen H, Keil U. Increasing prevalence of hay fever and atopy among children in Leipzig, East Germany. Lancet 1998; 351: 862-866.

8. Riikjärv M, Julge K, Vasar M, Brabäck L, Knutsson A, Björkstén $\mathrm{B}$. The prevalence of atopic sensitisation and respiratory symptoms among Estonian school children. Clin Exp Allergy 1995; 25: 1198-1204.

9. Dreborg S, Backman A, Basomba A, Bousquet J, Dieges $\mathrm{P}$, Malling H. Skin tests used in type I allergy testing. Position paper, prepared by the subcommittee on skin prick tests within the European Academy of Allergology and Clinical Immunology. Allergy 1984; 44: (Suppl. 10), $1-59$.

10. Hennekens $\mathrm{CH}$, Burning JE. Epidemiology in Medicine. Boston, Toronto 1987.

11. Braun-Fahrlander C, Gassner M, Grize L, et al. Comparison of responses to an asthma symptoms questionnaire completed by adolescents and their parents, SCARPOL team. Pediatr Pulmonol 1998; 25: 159-166.

12. Kulig M, Tacke U, Forster J, et al. Serum $\operatorname{IgE}$ levels during the first 6 years of life. J Pediatr 1999; 134: 453458.

13. Julge K, Munir A, Vasar M, Björkstén B. Indoor allergen levels and other environmental risk factors for sensitisation in Estonian homes. Allergy 1998; 53: 388-393.

14. Heinrich J, Wijst M. Increase of allergy in East Germany. Lancet 1998; 351: 1813.

15. Heinrich J, Richter K, Magnussen H, Wichmann HE. Is the prevalence of atopic disease in East and West Germany already converging? Eur J Epidemiol 1998; 14: 239-245.

16. Grünberg H, Mitt K, Thetloff M. Food habits and dietary intake of schoolchildren in Estonia. Scand J Nutr 1997; 41: 18-22.

17. Björkstén B. Allergy priming early in life. Lancet 1999; 353: $167-168$.

18. Strachan D, Butland B, Anderson H. Incidence and prognosis of asthma and wheezing illness from early childhood to age 33 in a national British cohort. BMJ 1996; 312: 1195-1199.

19. Lau Y, Karlberg J, Yeung C. Prevalence of and factors associated with childhood asthma in Hong Kong. Acta Paediatr 1995; 84: 820-822.

20. Henderson F, Henry M, Ivins S, et al. Correlates of recurrent wheezing in school-age children. Am J Respir Crit Care Med 1995; 151: 1786-1793.

21. Henry R, Bridgman H, Wlodarczyk J, Abramson R, Adler $\mathrm{J}$, Hensley M. Asthma in the vicinity of power stations. II. Outdoor air quality and symptoms. Pediatr Pulmonol 1991; 11: 134-140.

22. Peat J, van den Berg R, Green W, Mellis C, Leeder S, Woolcock A. Changing prevalence of asthma in Australian children. BMJ 1994; 308: 1591-1596. 